Eur $\mathrm{J}$ Clin Chem Clin Biochem

1995; 33:933-937

(c) 1995 Walter de Gruyter \& Co.

Berlin - New York

\title{
The Photoreactive Carbohydrate Probe, a Novel Method for Detection of Lectins
}

\author{
By Gordan Lauc, Karmela Barišić, Tihana Žanić and Mirna Flögel
}

Department of Biochemistry and Molecular Biology, Faculty of Pharmacy and Biochemistry, University of Zagreb, Zagreb, Croatia

(Received July 20/August 29, 1995)

Summary: One of the main difficulties in the research of lectins is the absence of an adequate technique for their specific and routine detection. Here, we present a photoreactive carbohydrate-probe which could help to overcome this problem. The probe was comopsed by joining four segments:

(i) a carbohydrate moiety,

(ii) the digoxigenin tag,

(iii) the photoreactive cross-linker and

(iv) the lysyl-lysine backbone.

After incubation with lectins in the dark, the probe can be activated and cross-linked to the lectins by illumination. The result is a lectin with covalently incorporated digoxigenin tag. Such a labelled lectin can be easily identified using anti-digoxigenin antibodies in a Western blot technique. This method is of high specificity and sensitivity and enables direct detection of lectins in complex mixtures, even whole cell homogenates.

\section{Introduction}

Almost all living cells contain a large number of different carbohydrate structures on their surface (1). The potential for encoding information contained in these carbohydrates is immense $(2,3)$. In peptides and oligonucleotides, the information content originates only from the number of monomeric units and their sequence, whereas in carbohydrates, information is also encoded in the position and anomeric configuration ( $\alpha$ or $\beta$ ) of the glycosidic unit, and in the occurrence of branching points (4). According to the current knowledge of the biosynthetic machinery which generates the carbohydrate structures, the glycosyltransferases responsible for the assembly process have highly specific substrate requirements and each enzyme generates only a very limited number of bonds $(5,6)$. Thus, the diversity existing in carbohydrate structures presumably arises from a multiplicity of synthetic enzymes, suggesting that information can be, and probably is encoded in carbohydrates.
Lectins are physiological receptors for glycoconjugates, thus being the molecules responsible for interpretation of information contained in carbohydrate structures (7). Although known for more than a century (8), lectins have only recently started to attract wider attention. This was mainly prompted by studies which demonstrated lectins as useful reagents for detection and isolation of glycoproteins (4). The idea that lectins may act in cell recognition originates from Harrison \& Chesterton, who proposed that a group of low $M_{\mathrm{r}} \beta$-galactoside-specific animal lectins, which they have called galaptins, might mediate adhesion via a cell-cell bridging mechanism (9). The background for this hypothesis was the realization that surface carbohydrates may function in cell recognition $(10,11)$, and demonstration that lectins are not confined to plants, as originally believed, but are ubiquitous in nature $(4,7)$.

The major obstacle in the research of lectins is the absence of an adequate technique for specific detection of carbohydrate-binding activity. Generally, it is first nec- 
essary to purify lectin by some kind of affinity chromatography, and only then it is possible to detect it with classical protein-staining methods $(12,13)$. Definitive proof that the protein eluted from the carbohydrate-affinity column is indeed a lectin is very hard to obtain. All currently existing methods measure only total sugarbinding activity in the sample, and cannot attribute this activity to a specific polypeptide, nor can they distinguish between two lectins of a similar specificity. In the case of proteins which are able to refold on a membrane after SDS PAGE and blotting, neoglycoproteins could serve this purpose (14), but this is not very often. Usually lectins lose their activity during SDS PAGE. The final proof that the protein of interest is indeed a lectin is possible only after cloning, i.e. when the presence of carbohydrate recognition domain is demonstrated (15).

\section{Materials and Methods}

Methods

5-Bromo-4-chloro-3-indolylphosphate, nitro blue tetrazolium, 4azidobenzoic acid-N-hydroxysuccinimide ester, lysyl-lysine, $a-D-$ glucopyranoside-phenylisothiocyanate and other carbohydrates were purchased from Sigma (St. Louis, MO); Immobilon PVDF membrane from Millipore (Bedford, MA), digoxigenin-3-Omethylcarbonyl- $\varepsilon$-aminocaproic acid-N-hydroxysuccinimide ester, anti-digoxigenin $F(a b)_{2}$ fragments labelled with alkaline phosphatase and anti-digoxigenin $\mathrm{F}(\mathrm{ab})_{2}$ fragments labelled with horse-radish peroxidase from Boehringer Mannheim (Mannheim), Bio-Gel P2 from Bio-Rad Laboratories (Hercules, CA).

\section{Concanavalin A ELISA}

Pro-Bind plates (Falcon) were precoated with Concanavalin A by $4 \mathrm{~h}$ incubation with $0.1 \mathrm{mg} /$ well Concanavalin A. After overnight blocking with $3 \%$ bovine serum albumin in phosphate-buffered saline, wells were incubated with samples (fractions from the gel filtration during purification of the photoreactive glucose probe) for 2 hours. After washing, wells were screened with anti-digoxigenin $\mathrm{F}(\mathrm{ab})_{2}$ labelled with horse-radish peroxidase, and developed with $0.04 \mathrm{~g} / \mathrm{l} o$-phenylenediamine in $0.05 \mathrm{~mol} / \mathrm{l} \mathrm{Na}$ citrate, 0.15 $\mathrm{mol} / \mathrm{l} \mathrm{Na}$ phosphate, $0.1 \mathrm{~g} / \mathrm{H}_{2} \mathrm{O}_{2}, \mathrm{pH}=5.0$ as a substrate.

\section{Thin-layer chromatography}

Purity of the $a-D$-glucose probe was analyzed by thin-layer chromatography (HPTLC Precoated plates, $0.2 \mathrm{~mm}$ thick kieselgel, $10 \times 10 \mathrm{~cm}$, Merck, Darmstadt) using chloroform: methanol: 40 $\mathrm{mmol} / / \mathrm{KCl}=50+42+11$ (by vol.) solvent system. The sample was applied, and the plate developed in a dark room under red light. After development the plate was cut into two halves. One half was stained for glucose-containing compounds, and the other for amino groups. For detection of glucose containing compounds plates were sprayed with resorcinol/ $/ \mathrm{HCl}$ reagent $(2 \mathrm{~g} / \mathrm{l}$ resorcinol; $0.25 \mathrm{mmol} / \mathrm{l} \mathrm{CuSO} \mathrm{S}_{4}$ in $10 \mathrm{~mol} / \mathrm{l} \mathrm{HCl}$ ). For detection of $\mathrm{NH}_{2}$-containing compounds plates were sprayed with $2.5 \mathrm{~g} / \mathrm{l}$ ninhydrin in $96 \%$ ethanol. Immediately after spraying, plates were layered onto an another glass plate (pre-heated to $100^{\circ} \mathrm{C}$ ), fastened with a pair of clips and maintained at $100^{\circ} \mathrm{C}$ until the colour developed.

\section{Cross-linking assay}

Eight $\mu$ l of protein sample were supplemented with $0.7 \mathrm{mmol} / 1$ $\mathrm{CaCl}_{2}$ and $0.5 \mathrm{mmol} / 1 \mathrm{MgCl}_{2}$. The $\mathrm{NaCl}$ concentration was adjusted to $250 \mathrm{mmol} / \mathrm{l}$. Two $\mu \mathrm{l}$ of $0.5 \mu \mathrm{mol} / 1 \alpha-D$-glucose probe were added to samples (final volume $=10 \mu \mathrm{l}$ ) and incubated 30 minutes in the dark at room temperature. Samples were cross-linked by illumination for $30 \mathrm{~s}$ in 'Strategene cross-linker, 1800'.

\section{Results and Discussion}

The photoreactive carbohydrate probe

To overcome the obstacles to the specific and routine detection of lectins we have designed a photoreactivecarbohydrate probe. The probe consists of four segments:

(i) the carbohydrate moiety,

(ii) the digoxigenin tag,

(iii) the photoreactive cross-linker and

(iv) the lysyl-lysine backbone.

The structure of the $\alpha-D$-glucose probe is shown in figure 1 . In this study only the synthesis and use of the $\alpha$ $D$-glucose probe will be described, but we have successfully applied analogous procedures for synthesis of galactose and mannose probes.

Lysyl-lysine was selected as backbone for the probe because it contains three spatially distant amino groups prone to chemical modifications. $\alpha-D$-Glucopyranosidephenylisothiocyanate was used to introduce a carbohydrate group into the lysyl-lysine backbone. This reagent is commercially available, and it was demonstrated that

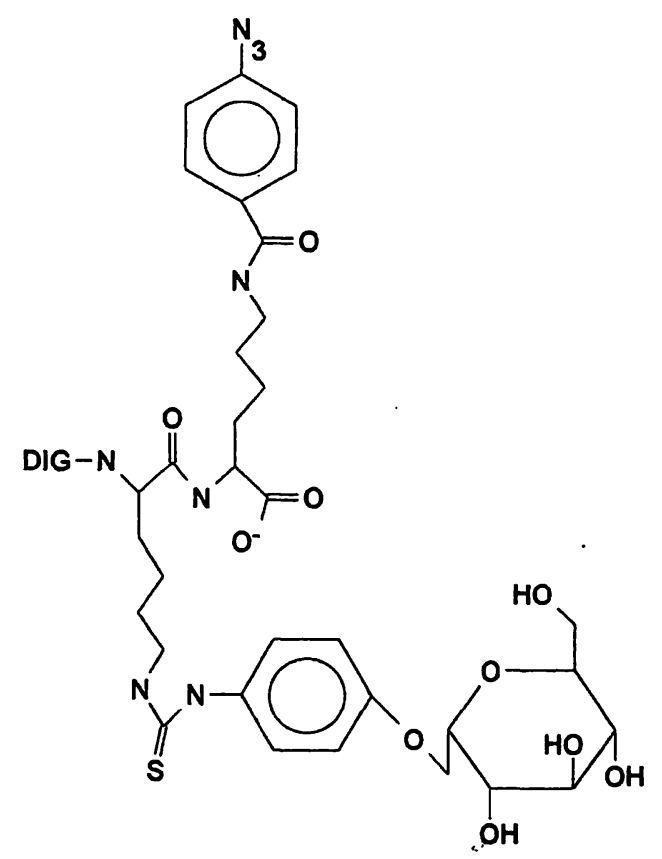

Fig. 1 Structure of the photoreactive $\alpha-D$-glucose probe. One of the possible structures is shown. The digoxigenin tag (DIG) is almost exclusively bound to the $\alpha$-amino group of the lysyllysine backbone. The $\alpha-D$-glucose and the photoreactive crosslinker are randomly distributed over the two $\varepsilon$-amino groups. 
the phenyl spacer does not interfere with the binding of $\alpha$-D-glucose to nuclear lectins (3). Digoxigenin, a commonly used molecular tag, was selected for a specific label because of its absence in mammalian tissues and commercial availability. Biotin was not used due to its presence in many tissues, especially liver. 4Azidobenzoic acid, a photoreactive cross-linker, was used to create a covalent linkage between the probe and the lectin. The 4-azidobenzoic acid is completely inert when incubated in the dark. However, when illuminated with UV light, the azide group is converted to a nitrene group which rapidly reacts with a variety of chemical bonds including $\mathrm{N}-\mathrm{H}, \mathrm{O}-\mathrm{H}, \mathrm{C}-\mathrm{H}$ and $\mathrm{C}=\mathrm{C}(16-18)$.

\section{Synthesis of the glucose probe}

Glc-Lys-Lys

As the first synthesis step the $\alpha-D$-glucose (Glc) tag was introduced into the lysyl-lysine backbone by reacting $\alpha-D$-glucopyranoside-phenylisothiocyanate with one of the amino groups of lysyl-lysine. One $\mathrm{mg}$ of $\alpha$ - $D$-glucopyranoside-phenylisothiocyanate was dissolved in $15 \mu \mathrm{l}$ dimethylsulphoxide and slowly transferred to $1 \mathrm{ml}$ lysyl-lysine solution under constant shaking. To prevent introduction of more than one glucose molecule into the probe, the molar ratio of $\alpha$ $D$-glucopyranoside-phenylisothiocyanate to lysyl-lysine was adjusted to $1: 5$. Reaction was performed for $4 \mathrm{~h}$ at room temperature in $0.1 \mathrm{~mol} / 1$ borate buffer (pH 8.8).

The reaction product (Glc-Lys-Lys) was separated from non-reacted $\alpha$ - $D$-glucopyranoside-phenylisothiocyanate and lysyl-lysine molecules by gel filtration through a Bio-Gel P2 column $(1 \times 150 \mathrm{~cm})$, equilibrated in $0.1 \mathrm{~mol} / 1$ borate buffer $(\mathrm{pH} \mathrm{7.4)}$. Eluted fractions were analyzed for the presence of glucose with the resorcinol sulphuric acid micromethod (19), and for the presence of $\mathrm{NH}_{2}$ groups with ninhydrin. Approximately $98 \%$ of glucose was found to be incorporated into the Glc-Lys-Lys complex and was eluted in the first peak $\left(\mathrm{V}_{\mathrm{e}} / \mathrm{V}_{\mathrm{o}}=1.44\right)$. Non-reacted lysyllysine and $\alpha-D$-glucopyranoside-phenylisothiocyanate co-eluted in the retarded fraction $\left(\mathrm{V}_{\mathrm{e}} / \mathrm{V}_{\mathrm{o}}=1.78\right)$.

\section{Glc-Lys-Lys-Dig}

The second step was the introduction of the digoxigenin label into the probe. Digoxigenin-3-O-methylcarbonyl$\varepsilon$-aminocaproic acid-N-hydroxysuccinimide ester $(0.3$ $\mathrm{mg}$ ) was dissolved in $15 \mu \mathrm{l}$ dimethylsulphoxide and added to the Glc-Lys-Lys solution. The labelling reaction was performed for $4 \mathrm{~h}$ at room temperature. The $\mathrm{pH}$ of 7.4 was used to assure that only one digoxigenin tag would be introduced. At this $\mathrm{pH}$ the $\varepsilon$-amino groups of lysyl-lysine are virtually completely protonated and only the $\alpha$-amino group can react with the hydroxysuccinimide ester. Because approximately $50 \%$ of the $\alpha$-amino groups in Glc-Lys-Lys complex were already occupied with the glucose label introduced in the previous step, the molar ratio of digoxigenin-3-O-methylcarbonyl- $\varepsilon$ aminocaproic acid-N-hydroxysuccinimide ester to GlcLys-Lys complex was set to $1: 3$.

The reaction product (Glc-Lys-Lys-digoxigenin complex) was separated from non-reacted molecules by a second gel filtration procedure applying the same column as above, but equilibrated and eluted with $0.1 \mathrm{~mol} / \mathrm{l}$ borate buffer $\mathrm{pH}=8.8$. Based on absorbance measurements more than $90 \%$ of the added digoxigenin-3-Omethylcarbonyl- $\varepsilon$-aminocaproic acid-N-hydroxysuccinimide ester was incorporated into Glc-Lys-Lys-digoxigenin complex and eluted as a first peak.

The identity of Glc-Lys-Lys-digoxigenin was confirmed using ELISA with concanavalin A-precoated plates as described in "Materials and Methods". As expected, the first peak gave positive result in the assay confirming the presence of molecular species which contain both glucose and digoxigenin. The second peak, containing Glc-Lys-Lys, gave negative result in the same assay.

The purity of the Glc-Lys-Lys-digoxigenin was analyzed by thin layer chromatography as described in "Materials and Methods". After chromatography the plate was cut in two halves and stained for sugars (with resorcinol) and for amino groups (with ninhydrin). Both stainings revealed the single band with $r_{e} / r_{f}=0.4$ which confirmed the assumed homogeneity of the probe (fig. 2).

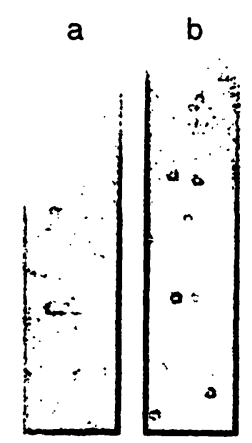

Fig. 2 Thin-layer chromatography of the photoreactive $\alpha-D$-glucose probe.

Five $\mu \mathrm{g}$ of Glc-Lys-Lys-digoxigenin were analyzed by thin layer chromatography on TLC plates using chloroform : methanol : 40 $\mathrm{mmol} / \mathrm{l} \mathrm{KCl}=50+42+11$ (by vol.) solvent system. Samples were applicd, and the plate developed in a dark room under red light.

Lane a, staining of sugar-containing compounds with resorcinol/ $\mathrm{HCl}$ reagent;

lane b, staining of $\mathrm{NH}_{2}$-groups with ninhydrin. 


\section{Glc-Lys-Lys-digoxigenin .}

The final synthesis step was the introduction of the photoreactive cross-linker into the probe. 4-Azidobenzoic acid-N-hydroxysuccinimide ester, $(0.3 \mathrm{mg})$ dissolved in $15 \mu \mathrm{l}$ dimethylsulphoxide, was added to the GlcLys-Lys-digoxigenin complex (molar ratio $2: 1$ ), and incubated at room temperature in the dark for $4 \mathrm{~h}$. Non-reacted hydroxysuccinimide was inactivated by addition of a surplus of $1 \mathrm{~mol} / \mathrm{l}$ ethanolamine $/ \mathrm{HCl}, \mathrm{pH}$ $=8.0$. After inactivation, the free 4-azidobenzoic acid$\mathrm{N}$-hydroxysuccinimide ester became monovalent (i.e. it contained only one group able to form covalent bonds with proteins) and lost the ability to cross-link. It remained together with the glucose probe, but did not pose any problems in the subsequent application of the probe.

\section{Application of the photoreactive glucose- probe}

A flow scheme for application of the photoreactive carbohydrate probe for detection of lectins is shown in figure 3.

(i) The probe is first incubated in the dark with lectincontaining samples.

(ii) After formation of the lectin-probe complexes, the samples are illuminated under an UV lamp to activate azidobenzoic acid, which then

(iii) covalently cross-links the probe to the lectin.

The product of the labelling reaction, a lectin with the covalently incorporated digoxigenin label, can be subse-

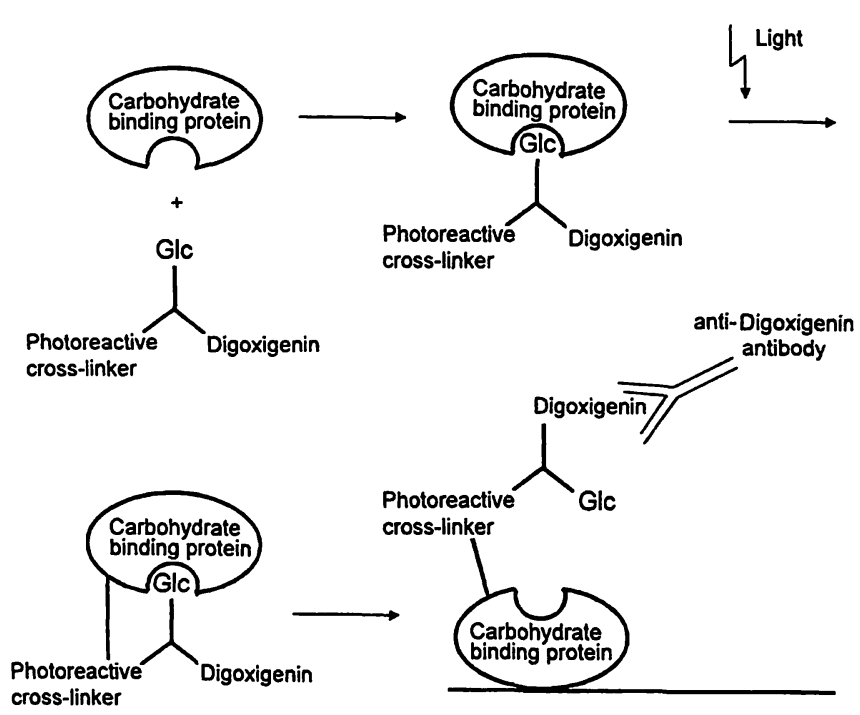

Fig. 3 A flow scheme for application of the photoreactive carbohydrate probe.

For specific labelling, the carbohydrate binding proteins were incubated together with the carbohydrate probe. For a detailed explanation see "Materials and Methods". quently detected by anti-digoxigenin antibodies. Due to the small relative molecular mass of the probe $\left(M_{\mathrm{r}}\right.$ $<1500$ ), labelled lectins can be easily identified by the Western blotting technique, following the electrophoretic separation of proteins.

Figure 4 demonstrates the specificity of the $\alpha-D$-glucose probe. The mannose/glucose specific lectin Concanavalin $A$ was detected by the $\alpha-D$-glucose probe in the presence of excess bovine serum albumin. Optimal concentrations of probe have to be chosen to obtain specific and sensitive signals (fig. 4). If the probe is used at exceedingly high concentrations $(>5 \mu \mathrm{mol} / \mathrm{l})$ unspecific labelling of protein occurs; as an example, bovine serum albumin and Concanavalin $\mathrm{A}$ are almost equally stained by the $\alpha-D$-glucose probe when the probe is used at a final concentration of $5 \mu \mathrm{mol} / \mathrm{l}$ (fig. 4). At optimal concentration (line $\mathrm{c}$ ) the probe specifically detects the lectin regardless of the presence of excess bovine serum albumin.

\section{Conclusion}

In this study we have introduced a new method for the detection of lectins using a photoreactive carbohydrate probe. The probe contains three vital parts:

(i) a carbohydrate moiety,

(ii) the digoxigenin tag, and

(iii) the photoreactive cross-linker.

After incubation with lectins in the dark, the probe can be activated and cross-linked to lectins by illumination, resulting in a lectin with the covalently incorporated digoxigenin tag. Such a labelled lectin can be easily identified by anti-digoxigenin antibodies using the Western blot technique.

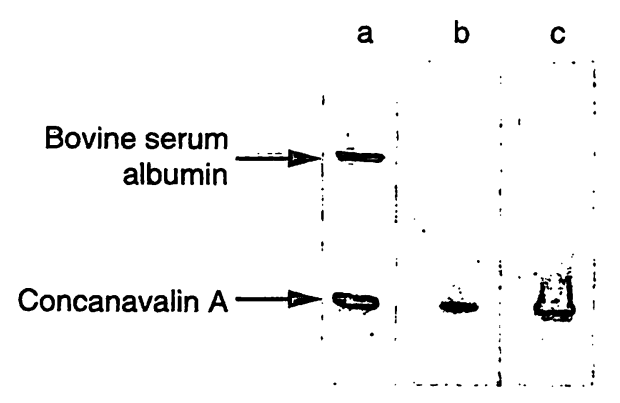

Fig. 4 Application of photoreactive $\alpha-D$-glucose probe. $\alpha-D$-Glucose probe was incubated with protein samples (final volume, $10 \mu \mathrm{l}$ ) for $30 \mathrm{~min}$ at $37^{\circ} \mathrm{C}$ in the dark and then illuminated with 7 camera flashes at a distance of $25 \mathrm{~cm}$. Samples were subsequently separated on $12 \%$ SDS PAGE (20), blotted to Immobilon PVDF membrane (21) and detected with anti-digoxigenin-alkaline phosphatase-conjugate. All samples contained $0.1 \mu \mathrm{g}$ Concanavalin $A$ and $1 \mu \mathrm{g}$ bovine serum albumin.

The final concentration of the $\alpha$ - $D$-glucose probe was $5 \mu \mathrm{mol} / \Omega$ (lane a); $0.01 \mu \mathrm{mol} / \mathrm{l}$ (lane b) and $0.1 \mu \mathrm{mol} / \mathrm{t}$ (lane c). 
This probe is the first method which enables direct detection and identification of lectins on a Western blot and it should be of a great help to all researchers studying changes in lectins under various conditions (e.g., development, ageing, stress, cancer etc.).

\section{References}

1. Cook GMW. Cell surface carbohydrates: molecules in search of a function? J Cell Sci 1986; Suppl 4:45-70.

2. Sharon N. Complex carbohydrates: their chemistry, biosynthesis and functions. Reading: Addison-Wesley, 1975.

3. Hughes RC. Glycoproteins. London: Chapman \& Hall, 1983.

4. Sharon N, Lis H. Lectins. London: Chapman \& Hall, 1989.

5. Drickamer K. Two distinct classes of carbohydrate-recognition domains in animal lectins. J Biol Chem 1988; 263:9557-60.

6. Lee YC. Sweet and sharply: ligands for lectins. Biochem Soc Trans 1993; 21:460-3.

7. Barondes S. Lectins: their multiple endogenous cellular functions. Annu Rev Biochem 1981; 50:207-31.

8. Stillmark H. Über Ricin, ein giftiges Ferment aus den Samen von Ricinus comm. L. und einigen anderen Euphorbiaceen. [Doctoral thesis] Dorpat: University of Dorpat, 1888.

9. Harrison FL, Chesterton CJ. Factors mediating cell-cell recognition and adhesion. Galaptins, a recently discovered class of bridging molecules. FEBS Lett 1980; 122:157-65.

10. Feizi T. Demonstration by monoclonal antibodies that carbohydrate structures of glycoproteins and glycolipids are oncodevelopmental antigens. Nature $1985 ; 314: 53-7$.

11. Feizi T. Carbohydrate differentiation antigens: probable ligands for cell adhesion molecules. Trends Biochem Sci 1991; 16:84-6.

12. Jia S, Wang JL. Carbohydrate binding protein 35 . Complementary DNA sequence reveals homology with proteins of the heterogenous nuclear RNP. J Biol Chem 1988; 263:6009-11.

13. Schröder HC, Facy P, Monsigny M, Pfeifer K, Bek A, Müller WEG. Purification of a glucose-binding protein from rat liver nuclei. Evidence for a role in targeting of nuclear $m R N P$ to nuclear pore complex. Eur J Biochem 1992; 205:1017-25.

\section{Acknowledgements}

This study was supported in part by a research grant \# 1-07-102 from the Ministry of Science and Technology of The Republic of Croatia.
14. Facy P, Sève A-P, Hubert M, Monsigny M, Hubert J. Analysis of nuclear sugar-binding components in undifferentiated and in vitro differentiated human promyelocytic leukemia cells (HL60). Exp Cells Res 1990: 190:151-60.

15. Drickamer K, Taylor ME. Biology of animal lectins. Annu Rev Cell Biol 1993; 9:237-64.

16. Bayley $\mathrm{H}$, Knowles JR. Photoaffinity labelling. Methods Enzymol 1977; 44:69-114.

17. Tae HJ. Bifunctional reagents. Methods Enzymol 1983; 580-609.

18. Wong SS. Chemistry of protein conjugated and cross-linking Boca Raton: CRC Press, 1991.

19. Monsigny M, Petit C, Roche AC. Colorimetric determination of neutral sugars by resorcinol sulfuric acid micromethod. Anal Biochem 1988; 175:525-30.

20. Laemmli UK. Cleavage of structural proteins during the assembly of the head bacteriophage T4. Nature 1970; 227:680-5.

21. Towbin H, Staehelin T, Gordon J. Electrophoretic transfer of proteins from polyacrylamide gels to nitrocellulose sheets: procedure and some applications. Proc Natl Acad Sci USA 1979; 76:4350-7.

\section{Dr. Gordan Lauc}

Department of Biochemistry and Molecular Biology Faculty of Pharmacy and Biochemistry

Domagojeva 2

HR-10000 Zagreb

Croatia 
, 